\title{
POLÍTICA DE REFORÇO ESCOLAR E ESTUDOS DE RECUPERAÇÃO NA REDE MUNICIPAL DE ENSINO: ENTRE O DITO E O FEITO.
}

\author{
VASCONCELOS ALVES, Ana Claudia Celice ${ }^{1}$ \\ BARREIRO de FREITAS, Iraíde Marques ${ }^{2}$
}

\begin{abstract}
Resumo
Este trabalho, em andamento, tem por objetivo analisar a proposta de reforço escolar e estudos de recuperação de uma rede municipal de ensino do interior paulista, no que concerne à implementação do programa nas escolas de $1^{\mathrm{a}}$ a $4^{\mathrm{a}}$ séries do Ensino Fundamental e à articulação entre os responsáveis pela proposta legal e os gestores das unidades escolares. Para análise nos fundamentamos na abordagem qualitativa. O reforço escolar e os estudos de recuperação fazem parte de propostas do sistema educacional brasileiro no combate ao fracasso escolar. Ao longo desses anos, são explicitados pela forma das políticas educacionais que os sistematizam e os legitimam. Parece haver, contudo, um distanciamento entre as iniciativas do poder público e a realidade articulada dentro da escola, passando a fazer parte deste estudo identificar elementos que compõem os desafios da implantação da proposta de reforço e recuperação, desde a rede municipal até as unidades escolares.
\end{abstract}

\section{Justificativa}

A partir da década de 70 ocorreram profundas transformações na estrutura da sociedade em nível mundial, principalmente em função da crise do capitalismo internacional. O novo papel do Estado, a reconfiguração dos serviços públicos, juntando-se aos novos rumos para a superação dessa crise do capital, repercutiram em modificações no processo de trabalho e, conseqüentemente, na definição das políticas educativas. (AZEVEDO, 2004, p. 6).

Reformas no âmbito da educação vêm sendo implementadas na maioria dos países periféricos, incluindo a América Latina, ao longo dos últimos anos, sob a determinação e forte influência de organismos internacionais e agências de financiamento, com maior destaque para o Banco Mundial (TORRES, 1996).

Sob o contexto da globalização e, portanto, do cenário neoliberal, no eixo dessas mudanças estão o que Torres (1996) chama de "pacotes de reforma", que na área da educação refere-se a uma série de diretrizes e medidas homogeneizantes e prescritivas, que vão "das macropolíticas até a sala de aula" (TORRES, 1996, p. 126). Em nome da modernização, vem-se adaptando a escola às exigências do mercado.

No caso do Brasil, especificamente no fim dos anos 80, ocorre a transição entre o regime militar e a retomada do processo de democratização. Muitos autores, inegavelmente, consideram que os movimentos em torno da Constituição de 1988 tendiam a um certo avanço nas esferas políticas, econômicas e sociais. (AZEVEDO, 2002; CAPANEMA, 2004; DRAIBE, 1990; SILVA, 1998). Uma possível aproximação rumo a uma social-democracia.

Certamente, o processo inicial de implementação da nova Lei de Diretrizes e

\footnotetext{
${ }^{1}$ Aluna do Programa de Pós-Graduação em Educação da Universidade Estadual Paulista - UNESP/Marília Rua Hemílio Magalhães, 68 - CEP 16010-490 - Araçatuba-SP - e-mail: avasc1@ isicmail.com.br

${ }^{2}$ Professora no Programa de Pós-Graduação em Educação da Universidade Estadual Paulista - UNESP/Marília e orientadora do trabalho.

Rua Antônio Morelli, 141 - CEP 19814-580 - Assis-SP - e-mail: iraide@ assis.unesp.br
} 
Bases da Educação Nacional no 9.394 de 1996 (LDB de 96), que se deu em meados da década de 80, dava sinais de novas perspectivas para uma escola pública de qualidade, envolvendo nas discussões vários setores da sociedade civil e política que demonstravam interesse nas questões educacionais. Entretanto, o projeto inicial foi sendo minado por forças provenientes de uma nova lógica que vinha (e ainda vem) concretizando os princípios neoliberais no país.

Instalava-se certo desânimo com os encaminhamentos e o desfecho da nova lei. Além de ser uma possibilidade desperdiçada de mudanças efetivas, era uma oportunidade de viabilização da construção de um sistema educacional mais aberto, abrangente, voltado às necessidades da sociedade brasileira como um todo. (SAVIANI, 1997, p. 229). Por outro lado, a nova LDB trouxe alterações importantes e significativas para a educação básica do país, porém ainda encontrava-se mergulhada entre contradições ou omissões, "seja pelo dito, seja pelos aspectos em que silencia" (PEREIRA e TEIXEIRA, 2000, p. 99).

Penin (2000), em documentação oficial - obviamente numa outra perspectiva cita com veemência que um dos pontos principais na compreensão de novos caminhos colocados pela LDB de 1996 à educação brasileira é o de ter criado condições legais para que a escola se organize para alcançar seus objetivos, com flexibilidade e autonomia.

Segundo Martins (2002), muitas das recomendações de organismos internacionais apontavam a crise da educação como agravante dos problemas sociais e econômicos dos países. Em virtude disso, justifica-se, frente a esse contexto, a incorporação no texto da LDB 9.394/96 ${ }^{3}$ de medidas como, por exemplo, a flexibilidade curricular e a organização administrativo-financeira, a implementação de processos de descentralização e a autonomia das redes de escolas, onde, efetivamente, percebem-se "algumas tendências internacionais em relação às concepções norteadoras para as reformas da área" (MARTINS, 2002, p. 128). Para a autora, essas medidas, indubitavelmente, estariam ligadas a uma nova forma de gestão do sistema nacional de ensino.

Seguindo essa mesma lógica, constata-se no discurso (e na materialização) das políticas educacionais a importância do processo de descentralização da gestão dos sistemas educativos, sob a justificativa da democratização da escola pública, racionalização de recursos, buscando melhorar a qualidade do ensino. Ocorre, conseqüentemente, a indução à municipalização do ensino, o que, da forma como vem sendo gerida, requer profundas alterações na sua estrutura.

Diante desse quadro de conflitos e ambigüidades e, possivelmente em virtude dele, os resultados da efetivação de muitas propostas político-educacionais de maior abrangência, especialmente as voltadas à estruturação do ensino - seja no âmbito organizacional, seja no âmbito didático-pedagógico - encontram-se no eixo entre o que legalmente se propõe e o que se comprova no interior das escolas.

Há um ponto de extrema importância a ser levado em consideração: ao tomar como exemplo o aumento significativo do número de matrículas no ensino fundamental, considerando os esforços para a universalização e democratização do ensino, ainda muitas indagações permeiam a questão da qualidade do ensino:

\footnotetext{
${ }^{3}$ Não somente nesta lei, mas em todo um conjunto legal e normativo que orientariam a política educacional brasileira (MARTINS, 2002).
} 


\begin{abstract}
(...) esse crescimento quantitativo das oportunidades de acesso à escola pública, na medida mesmo em que possibilitou que significativos contingentes de alunos das camadas populares a freqüentem, trouxe, como problemática fundamental, a questão da precariedade da qualidade do ensino ministrado e, por conseguinte, da impropriedade das políticas educativas que têm sido implementadas para equacionar os problemas da repetência, da evasão e do desempenho - enfim, da garantia de processos efetivos de escolarização que combatam as desigualdades educacionais. (AZEVEDO, 2002, p. 50)
\end{abstract}

Mesmo tratando da construção da cidadania nos preceitos da lei, MACHADO (1998, p. 95) ressalta que o ajustamento da escola às prescrições oficiais está ligado ao ordenamento interno da mesma, incluindo toda uma multiplicidade de fatores do contexto escolar. O cotidiano da escola também é colocado por AZEVEDO (2004, p. 59) como o elo final de uma cadeia complexa para se dar concretude a um programa de ação.

Há que se considerar, também, que existe uma relação muito próxima entre as políticas educacionais, a organização e gestão das escolas, e as práticas pedagógicas. (LIBÂNEO, 2004).

Os programas de reforço e recuperação de aprendizagem, objetos desta pesquisa, surgem, dentre outras tantas ações do poder público, como uma das medidas de melhoria da qualidade do ensino e da minimização do fracasso escolar. Poder-se-ia inferir, a partir das colocações anteriores, que esses programas de reforço e recuperação, impulsionados e caracterizados, por um lado, pelas diretrizes legais, encontrariam forma na intencionalidade da ação escolar a que estão submetidos.

$\mathrm{O}$ interesse pelo aprofundamento teórico sobre esta temática é proveniente de inquietações advindas do contato desta pesquisadora com uma escola pública municipal. $\mathrm{Na}$ tentativa de enfrentar o fracasso escolar de alunos que, após longos anos de escolaridade, ainda não se apropriavam da escrita e da leitura de forma autônoma (possivelmente pelos fatores repetência e/ou evasão), esta escola procurou proporcionar aos educandos um trabalho específico e diferenciado de reforço e recuperação de aprendizagem que, em apenas um ano letivo, apresentou resultados consideráveis.

O que mostrava-se intrigante era o fato de que este trabalho era um movimento isolado dentro daquele sistema municipal de ensino, visto que em outras escolas da mesma rede não se percebiam ações semelhantes. Parecia configurar-se um distanciamento entre o que estava prescrito na legislação educacional local e o que, efetivamente, ocorria na realidade escolar. A partir desta experiência surgem alguns questionamentos: os movimentos dentro da escola estariam vinculados e/ou dependentes de iniciativas isoladas de gestão? Estaria isso relacionado à fragilidade das políticas que tanto preconizam a flexibilidade, a descentralização e a autonomia?

A partir de então, foi freqüente o envolvimento da pesquisadora com leituras, além da participação em encontros, debates e palestras. Um primeiro ensaio para um estudo mais sistematizado se deu na elaboração de um projeto de pesquisa, exigência para conclusão do curso de especialização em Gestão Educacional. Tal experiência não bastou em si. Pelo contrário, suscitou o desejo de intensificação dos estudos.

O contato com outra rede municipal de ensino trouxe novas indagações a antigos problemas. Há ainda muitas dúvidas sobre a maneira como se tem dado a implementação do programa de reforço escolar e dos estudos de recuperação nas escolas 
públicas, neste caso, particularmente, as submetidas ao processo de municipalização do ensino fundamental. Destacamos as seguintes: quais são os desafios enfrentados pelas escolas municipais de Ensino Fundamental quanto à implementação do programa de estudos de recuperação e reforço escolar? Há preocupação, no âmbito das prerrogativas legais, em reconhecer as especificidades e as demandas reais das diferentes escolas? Como se dá a articulação entre os responsáveis pela proposta legal e os gestores das unidades escolares?

\section{Introdução}

Ao ser o espelho da realidade social brasileira, a escola vem sendo submetida ao autoritarismo e elitismo, que constituíram a base do sistema educacional por um longo tempo. Certamente, as mudanças sociais que percebemos na atualidade requerem novas demandas de formação e conhecimento. No entanto, o direito à escolaridade básica de qualidade não tem sido garantido à maior parte da população. É clara a inadequação das políticas educativas empreendidas, notando-se, sobretudo, não só a permanência como o agravamento da desigualdade social no país. (AZEVEDO, 2004, p. 8).

Na década de 1980, transcorridos cinqüenta anos da implementação de uma política educacional no país ${ }^{4}$, pesquisas já revelavam "uma cronificação deste estado de coisas praticamente imune às tentativas de revertê-lo" (PATTO, 1999, p. 19), referindo-se às proporções inaceitáveis dos índices de reprovação e evasão na escola pública do então primeiro grau. Os dados que apontavam para o fracasso escolar evidenciavam tentativas de educadores progressistas e políticos em garantir a escolarização para as classes populares, mas que não passavam de promessa, sonho e desejo.

Nesse mesmo estudo da autora, foram apontados os mais variados enfoques sob os quais as crianças fracassadas eram submetidas, com o intuito de justificar as diferentes participações dos sujeitos no âmbito escolar, que vão desde déficits individuais a diferenças culturais. Ela sugeria, na época, uma análise mais cautelosa a respeito da inadequação da escola frente a esses alunos, pela baixa expectativa em relação à sua clientela, pela freqüente prática irreflexiva e, obviamente, pela sua má qualidade. Para Patto (1999), o fracasso da escola era resultado de um sistema educacional que obstruía a realização dos seus objetivos.

Fazendo um recorte sobre a questão dos programas de recuperação e reforço escolar - objeto deste estudo - bem como as dimensões e implicações das políticas que o implementam, faz-se necessário analisar, grosso modo, no corpo da legislação das últimas décadas, quais os preceitos da lei que direcionam essas e outras ações no âmbito da educação.

Desde a Lei $\mathrm{n}^{\circ} 5.692 / 71$, foram implantados tais estudos de recuperação a fim de garantir melhor aproveitamento aos discentes que, durante o percurso escolar, apresentassem aprendizagem insuficiente ${ }^{5}$. Surgindo como uma salvação para o problema da repetência, pois sua obrigatoriedade era prevista por lei, o objetivo era recuperar notas para a

\footnotetext{
${ }^{4}$ Segundo Patto (1999) e Ghiraldelli Junior (2000), apenas a partir da Constituição de 1934 é que se instituiu uma política educacional mais abrangente, compreendendo o ensino de todos os graus bem como sua regulamentação.

${ }^{5}$ Artigo 11 , parágrafo $1^{\circ}$ da Lei $n^{\circ} 5.692 / 71$ : “Os estabelecimentos de ensino de $1^{\circ}$ e $2^{\circ}$ graus funcionarão entre os períodos letivos regulares para, além de outras atividades, proporcionar estudos de recuperação aos alunos de aproveitamento insuficiente..."; Artigo 14, parágrafo $2^{\circ}$ da mesma lei: "O aluno de aproveitamento insuficiente poderá obter aprovação mediante estudos de recuperação proporcionados obrigatoriamente pelo estabelecimento."
} 
possível aprovação do aluno. Neste caso, o conceito de recuperação parecia estar relacionado mais à questão da aprovação do que a apropriação do conhecimento.

Com a implementação da LDB 9.394/96, uma série de ações ${ }^{6}$, inseridas em um novo contexto para o ensino público, vêm tentando sistematizar e legitimar propostas voltadas à superação do fracasso escolar. Entre elas, os estudos de recuperação e reforço, que surgem reconfigurados, mantendo sua obrigatoriedade ${ }^{7}$, igualmente garantida na lei anterior (Lei 5.692/71), entretanto parecem emergidos numa perspectiva que demonstra uma maior preocupação com a qualidade da aprendizagem. Vale lembrar que uma das tarefas mais importantes, na atualidade, é definir que tipo de qualidade é esta, quando se predomina princípios neoliberais, como produtividade, competitividade, adaptabilidade, ajuste ao mercado, etc. (PEREIRA e TEIXEIRA, 2003, p. 97-98).

No caso do Estado de São Paulo, a Secretaria de Estado da Educação (SEE) implementa ampla reestruturação da rede de ensino paulista, desencadeada a partir de $1995^{8}$. Estas ações, conforme discurso da SEE, procuravam dar suporte e preparar a rede para atuar no sentido de buscar garantir o acesso, a permanência e a aprendizagem contínua, progressiva e bem-sucedida para todos os alunos.

Neste mesmo Estado, a deliberação do Conselho Estadual de Educação, CEE n 9 de 1997 instituiu, a partir da adoção do Regime de Progressão Continuada (incluindo a organização em ciclos plurianuais), a substituição do conceito de aprovação/reprovação pelo de "aprendizagem progressiva e contínua". Tal conceito aparece nos documentos oficiais da SEE, assim como no intitulado "A Escola de Cara Nova: Planejamento 2000". Ressalta-se a alteração radical do percurso escolar. "Se antes, ao final de cada ano letivo, aprovava-se ou reprovava-se os alunos com base no desempenho [...], espera-se agora, que a escola encontre maneiras de ensinar que assegurem a efetiva aprendizagem de sua clientela e, consequentemente, seu progresso intra e interciclos".

A intencionalidade da proposta legal pretendia dar nova roupagem às concepções de ensino e aprendizagem, bem como às estratégias de recuperação, sempre no intuito de proporcionar melhores resultados.

Visto, então, como uma boa saída para se resolver dois "nós" dentro do

\footnotetext{
${ }^{6}$ Partindo dos princípios emanados da Constituição Federal de 1988, a nova LDB estabelece uma redefinição do papel da escola pública, o que implica ações voltadas para a garantia da qualidade do ensino, abrangendo uma nova concepção para a educação básica: possibilidade de adoção do regime de progressão continuada no ensino fundamental, modificações na organização curricular; além da desburocratização da educação (WEY, 2002).

${ }^{7}$ Artigo 24, inciso V, alínea "e" da LDB 9.394/96:

Artigo 24. A educação básica, nos níveis fundamental e médio, será organizada de acordo com as seguintes regras comuns:

(...)

$V$ - a verificação do rendimento escolar observará os seguintes critérios:

(...)

e) obrigatoriedade de estudos de recuperação, de preferência paralelos ao período letivo, para os casos de baixo rendimento escolar, a serem disciplinados pelas instituições de ensino em seus regimentos;

${ }^{8}$ Reorganização da rede; extensão da presença em todas as escolas do Professor Coordenador Pedagógico (PCP); trabalho com indicadores de resultados educacionais; Projeto das Classes de Aceleração; capacitação em serviço (PEC: Programa de Educação Continuada); descentralização em SP da aquisição de livros didáticos; e o Programa de Reforço e Recuperação (SEE, 2000).
} 
sistema educacional, o pedagógico e o estatístico ${ }^{9}$, esperava-se que a implementação da Progressão Continuada, enquanto política pública, proporcionasse um resultado mais favorável, voltado para mudanças e reformulações significativas que garantissem a aprendizagem e o acesso ao conhecimento. Entretanto, o resultado mais evidente produzido foi a redução dos índices de evasão e repetência, o que em si é relevante, embora longe de ser suficiente $^{10}$, uma vez que seria necessário, também, que se levasse em conta o fator qualidade $^{11}$.

Paralelo a toda essa movimentação, os anos 90 foram marcados pela crescente radicalização do processo de municipalização do ensino, materializando o princípio da descentralização, na esteira das tendências internacionais. $O$ foco encontrava-se (e ainda encontra-se) no aumento da eficácia e da eficiência dos sistemas educacionais, sob a modernização da gestão pública. O discurso da política educacional, tomando como exemplo o caso específico do Estado de São Paulo, salienta a "necessidade de se democratizar e ampliar a participação dos usuários da rede pública de ensino por meio do fortalecimento do poder local" (MARTINS, 2003, p. 528-529).

Esse enfoque "descentralista", entretanto, parece estar muito mais ligado à simples transferência de responsabilidades financeiras do Estado para os municípios, a exemplo de uma das medidas de maior impacto no processo de municipalização: a criação do FUNDEF $^{12}$. Há, efetivamente, um “descompromisso em relação às metas de expansão das matrículas e de instauração da melhoria da qualidade do ensino”. (ibid, 2002, p. 127).

Frente a tais colocações, é possível inferir que a imposição de medidas por meio da legislação não se constitui em garantia para o progresso dos alunos. Muitas questões surgem, ainda sem respostas: qual a preocupação, então, dos governos locais quanto à implementação de políticas que, de fato, tragam resultados positivos? Qual a perspectiva desta nova tendência ao ajuste da gestão dos sistemas de ensino e das escolas ao modelo gerencial? Fruto deste processo de descentralização, caberia a cada escola, como unidade autônoma, apenas colocar em ação as decisões tomadas pelo poder central? Poderíamos, neste caso, chamar de desconcentração? É esta a autonomia que tanto preconizam os dispositivos legais?

Esta pesquisa buscará analisar as dimensões da proposta de reforço escolar e estudos de recuperação, enquanto política pública, bem como sua implementação nas escolas municipais de $1^{\mathrm{a}}$ a $4^{\mathrm{a}}$ séries (Ensino Fundamental), de um município do interior paulista, considerando os elementos que fazem parte da articulação entre os responsáveis pela proposta legal, neste caso a secretaria municipal de ensino, e os gestores das unidades escolares.

\footnotetext{
9 Em 1992, no Brasil, a taxa de repetência na $1^{\text {a }}$ série do Ensino Fundamental era superior a $60 \%$ (PCN Introdução, 1997).

${ }^{10} \mathrm{Em} 2003$, encontram-se na casa dos $33 \%$ os índices de evasão e repetência na $1^{\text {a }}$ série do ensino fundamental (Inep/MEC).

11 Ainda que limitados, os dados do Sistema Nacional de Avaliação da Educação Básica (SAEB), de 2003, apontam: 55\% dos estudantes da $4^{\mathrm{a}}$ série do EF encontravam-se nos níveis "muito crítico" e "crítico", demonstrando competência de leitura abaixo de um nível considerado apropriado à série. Apenas 5\% apresentavam nível adequado.

${ }^{12}$ A Emenda Constitucional 14/96, regulamentada pela Lei n ${ }^{\circ}$ 9.424/96, cria o FUNDEF - Fundo de Manutenção e Desenvolvimento do Ensino Fundamental e de Valorização do Magistério.
} 


\section{Objetivos:}

Analisar os elementos pertinentes à proposta de reforço escolar e recuperação de uma rede municipal de ensino, bem como os mecanismos para sua implementação;

Analisar como se configura a proposta de reforço e recuperação nas unidades escolares, no que concerne à gestão, obtendo elementos da articulação entre gestores e docentes;

Identificar os elementos da articulação entre os responsáveis pela proposta legal e os gestores das unidades escolares.

\section{Desenvolvimento e procedimentos metodológicos:}

No intuito de buscarmos respostas a tais questionamentos, através do estudo de caso, utilizaremos como campo de pesquisa a Secretaria Municipal de Educação de Araçatuba, município do interior do estado de São Paulo e três escolas de Ensino Fundamental desta mesma rede de ensino. Por meio de entrevistas semi-estruturadas, análise de bibliografia e documentação pertinente, apontamos nosso trabalho para uma abordagem qualitativa.

Entrevistaremos a equipe de coordenação pedagógica da Secretaria Municipal a fim de analisarmos os elementos pertinentes ao programa de reforço escolar e recuperação desse sistema municipal, bem como os mecanismos para sua implementação. Entrevistaremos, também, os gestores das respectivas unidades escolares, para que possamos analisar como se configura a proposta de reforço e recuperação na unidade escolar. Além das entrevistas, outros instrumentos serão utilizados, como a observação e a análise documental. A observação poderá englobar os momentos de orientação e acompanhamento da equipe de coordenação pedagógica da secretaria de educação local aos gestores das unidades escolares, o que nos permitirá identificar os elementos da articulação entre os responsáveis pela proposta legal e os gestores da unidade escolar. A observação incluirá, também, os momentos de trabalho pedagógico da equipe escolar (HTPCs), o que nos proporcionará analisar as características pertinentes à gestão no que concerne à implementação do programa na unidade escolar, obtendo elementos da articulação entre gestores e docentes das unidades.

A partir dos dados levantados e estudos teóricos, poderemos estabelecer relações entre a proposta legal e a efetiva implementação do programa de reforço e recuperação nas escolas. A análise documental constituir-se-á, nesse caso, em complementação das informações obtidas por outras técnicas (LÜDKE e ANDRÉ, 1986, p. $38)$.

\section{Conclusões}

A etapa inicial da pesquisa não nos permite ainda tecer considerações de cunho conclusivo, visto que ainda nos encontramos na fase de levantamento e estudo da bibliografia, que serve de estrutura básica para a pesquisa.

Longe da pretensão de abordar o tema por completo, cremos na relevância deste estudo como forma de obtenção de elementos preciosos para a análise das dimensões e implicações que norteiam o processo de implementação das políticas públicas. 


\section{Referências bibliográficas}

Azevedo, J. M. L. (2002). Implicações da nova lógica de ação do Estado para a educação municipal. Educação \& Sociedade, 23(80), 49-71.

Associados.

(2004) A educação como política pública. $3^{\mathrm{a}}$ ed. Campinas: Autores

Capanema, C. F. (2004). Gênese das mudanças nas políticas públicas e na gestão da educação básica. In: Bittar, M., Oliveira, J. F (Orgs.), Gestão e políticas da educação. (pp. 36-52). Rio de Janeiro: DP\&A.

Draibe, S. M. (1990) As políticas sociais brasileiras: diagnósticos e perspectivas. In: Para a década de 90: prioridades e perspectivas de políticas públicas. (pp. 01-66). Brasília: IPLAN/IPEA.

Ghiraldelli Junior (2000). História da Educação. $2^{\mathrm{a}}$ ed. São Paulo: Cortez.

Libâneo, J. C. (2004) Organização e gestão da escola: teoria e prática. $5^{a}$ ed. Goiânia: Editora Alternativa.

Lüdke, M. e André, M. E. D. A. (1986). Pesquisa em educação: abordagens qualitativas. São Paulo: EPU.

Machado, L. M. (1998). A nova LDB e a construção da cidadania. In: Silva, C. S. B. e Machado, L. M. (Orgs.), Nova LDB: trajetória para a cidadania? (pp. 93-104). São Paulo: Arte \& Ciência.

Martins, A. M. (2002). Autonomia da escola: a (ex)tensão do tema nas políticas públicas. São Paulo: Cortez.

(2003). A política educacional paulista: controvérsias em torno dos conceitos de descentralização e autonomia - 1983 a 1999. Educação \& Sociedade, 24(83), 527-549.

Patto, M. H. S. (1996) A produção do fracasso escolar: histórias de submissão e rebeldia. São Paulo: TA Queiroz.

Penin, S T S. (2000) Qualidade de ensino e progressão continuada. In: A Construção da proposta pedagógica da escola: a escola de cara nova. Planejamento 2000. São Paulo: SEE.

Pereira, E W e Teixeira, Z A. (2000). A educação básica redimensionada. In: Brzezinski, I. LDB interpretada: diversos olhares se entrecruzam. $3^{\mathrm{a}}$ ed. (pp. 87-109). São Paulo: Cortez.

Saviani, D. (1997). A nova lei da educação: trajetórias, limites e perspectivas. Campinas-SP: Autores Associados.

Silva, C. S. B. (1998). A nova LDB: do projeto coletivo progressista a legislação da aliança neoliberal. In: Silva, C. S. B. e Machado, L. M. (Orgs.), Nova LDB: trajetória para a cidadania? (pp. 93-104). São Paulo: Arte \& Ciência. 
Torres, R. M. (1996). Melhorar a qualidade da educação básica? As estratégias do Banco Mundial. In: Tommasi, L. D.; Warde, M. J. e Haddad, S. (Orgs.) O Banco Mundial e as Políticas Educacionais. São Paulo: Cortez.

Wey, V. L.(coord.). (2002). "Progressão continuada da aprendizagem: o que falta dizer sobre sua implantação." Fórum de debates: progressão continuada: compromisso com a aprendizagem. Disponível em http://www.crmariocovas.sp.gov.br [acessado em 25/07/2005].

\section{Legislação e documentos legais:}

BRASIL. Lei $n^{\circ}$ 5692/71 de 11 de agosto de 1971 - Lei de Diretrizes e Bases para o Ensino de 1 o e 20 graus.

BRASIL. Lei no 9394/96 de 20 de dezembro de 1996 - Lei de Diretrizes e Bases da Educação Nacional. Brasília.

BRASIL. Ministério da Educação e Cultura. Instituto Nacional de Estudos e Pesquisas Educacionais Anísio Teixeira. Censo Educacional. Disponível em http://www.inep.gov.br/ acessado em 05/09/2005.

BRASIL. Ministério da Educação e Cultura. Instituto Nacional de Estudos e Pesquisas Educacionais Anísio Teixeira. SAEB. Disponível em http://www.inep.gov.br/ [acessado em 09/09/2005].

BRASIL. Secretaria de Educação Fundamental. (1997). Parâmetros Curriculares Nacionais: introdução aos Parâmetros Curriculares Nacionais. Brasília: MEC/SEF.

SÃO PAULO. Conselho Estadual de Educação. Deliberação no 9/97, de 30 de julho de 1997 - Institui, no Sistema de Ensino do Estado de São Paulo, o Regime de Progressão Continuada no Ensino Fundamental. Disponível em http://www.ceesp.sp.gov.br [acessado em 02/08/2005].

SÃO PAULO. Secretaria de Estado da Educação. (2002). A construção da proposta pedagógica da escola - A escola de cara nova - Planejamento 2000. São Paulo. 